\title{
Electricity Price Forecasting using a Hybrid of Neural Network and Genetic Algorithm
}

\author{
N.N.A.N. Ibrahim, I.A.W.A. Razak, Z.H. Bohari
}

\begin{abstract}
Electricity price forecasting has gained a reputation for its importance in the deregulated energy market. The forecast process can be complicated as it depends on many elements. This paper proposes a hybrid of a neural network with a genetic algorithm for the electricity price forecasting. The Ontario energy market is select as the tested market for this model. The features for the neural network input are the actual historical demand and actual Hourly Ontario Energy Price (HOEP). The genetic algorithms help to select the number of features and to optimize the parameters of the neural network. This hybrid model helps to improve the accuracy of the forecasted price when comparing with the accuracy of the individual neural network itself. The mean absolute percentage error has represented the accuracy of the hybrid model, and it is used as a benchmark of the proposed hybrid model with other models.
\end{abstract}

Keywords: Electricity price forecasting, Genetic Algorithm Neural Network, short-term forecasting.

\section{INTRODUCTION}

The regulated energy market had been controlling the electricity industry for many decades. The regulated electricity market means that the utility is in a vertically integrated ownership system that has full control over the generation. The regulation provides a stable industry and price, and lead to the success of the universal power grid extended through all cities and rural areas. However, the regulation and deficiency competition had caused a type of stagnation. Therefore, there are several moves to drive the government to deregulate its energy industry. The deregulation led to more competition, which encourages the development of the energy industry, innovation, and even gave out more extensive choice and at a lower price [1].

In the deregulated electricity market, the electricity price may be a barrier as it relies on many uncertainty factors such as weather, supply, demand, the global market, etc. As such, the electricity price forecasting has become a vital device to predict the electricity price since the price can have a sudden spike price and extremely volatile. Many forecasting models had been proposed such as CGSA-LSSVM [2], ARMAXGARCH [3], GRBFN [4], WT with ARIMA-GARCH [5], etc.

The machine learning receives lots of attention as it requires adaptive mechanisms that allow the computers to learn from experiences such as examples and analogy. The most popular methods of machine learning are artificial neural networks and genetic algorithms [6]. From past

Revised Manuscript Received on October 23, 2019.

N.N.A.N. Ibrahim, Faculty of Electrical Engineering, Universiti Teknikal Malaysia Melaka (UTeM), 76100, Malacca, Malaysia.

I.A.W.A. Razak, Industrial Power Department of Faculty of Electrical Engineering / Center for Robotics and Industrial Automation (CeRIA), Universiti Teknikal Malaysia Melaka (UTeM), 76100, Malacca, Malaysia.

Z.H. Bohari, Faculty of Electrical and Electronic Engineering Technology, Universiti Teknikal Malaysia Melaka (UTeM), 76100, Malacca, Malaysia. researchers, many had proposed artificial neural networks [7]-[13].

The artificial neural network (ANN) has earned much recognition due to the non-parametric data-driven models and has the ability to mapping a nonlinear function. The ANN was also known due to its smooth and simple models. However, by using the neural network itself may lead to local minima and the genetic algorithms suggested to overcome such issues [14], [15].

In this paper, the hybrid of the neural network and genetic algorithm is proposed for the Ontario energy market. The feed-forward neural network is used for the neural network models. The purpose of this hybrid method is to enhance the accuracy of the forecasted electricity price when comparing it with the single neural network itself.

\section{IMPLEMENTATION OF NEURAL NETWORK AND GA}

The neural network can be illustrated as the human brain. The neural network imitates the brain concept; the information is stored and processed simultaneously throughout the whole network [6], [16]. The network changes its connection weights by training to learn the solution to a particular issue. Its architecture and algorithm determine the learning ability of the neural network for training [17].

Genetic algorithms (GAs) are based on natural selection and genetics. The genetic algorithm takes the trait of the evolutionary optimization characteristic in optimizing a process to produce a better solution to a 'bad situation'. The primary mechanism of GAs is simple as it involves in copy string of individuals and flips partial of the strings. It is capable of being applied to a wide range of severe problems The GAs can aid in searching the optimal answer after a few iterative performances [18].

The GAs is used to optimize the feature and parameter of the neural network. The GAs is initialized with 'population guesses' that are typically random and will then be spread across the search area. These initial guesses are in the binary alphabet (or strings) of the real variables which also known as the chromosomes. A set of solutions that represents by the chromosomes is known as population [19]. The GAs will train the feature and parameter using the three operators: selection; crossover; and mutation, to guide the population towards achieving optimum global convergence [20].

Published By: 


\section{ELECTRICITY PRICE FORECASTING USING A HYBRID OF NEURAL NETWORK AND GENETIC ALGORITHM}

The selection applies pressure to the population by removed the feeble performing individuals, which allowed the capable individuals to have a chance of promoting the information within for the next generation. The crossover gives out a solution to exchange information. The operator chose a random pair of two individuals promoted by the selection for mating (exchange all information between two individuals) then the mutations will randomly flip a bit in the string [19]. After these operations are applied to the first generation, a new generation is formed [20].

There are few factors affecting the GAs performance, all of which includes the population size, number of generations, rate of crossover, and rate of mutation. Having a bigger size of population and generations can raise the chance of achieving the global optimum; however, it may increase the computational time [18], [21].

\section{METHODOLOGY}

The actual historical demand and HOEP is obtained from the data directory of IESO [22]. The training period is set for the past 49 days as a fair comparison with the previous research [23].

From Table I, six models are developed to represent the three seasons of spring, summer, and winter in the year 2004. Week one and week two are in the spring seasons, week three and week four are in the summer seasons, while week five and week six are in the winter seasons.

For the neural network feature, the actual past demand and HOEP are used. For the actual past demand, previous day-1, day-2, and day-7 are used while for the HOEP, and previous day- 1 is used as the neural network feature. The notation day-n represents the previous day data from the testing day. The initial feature for the neural network is 96 . The feature is chosen based on the evaluation of the correlation analysis, which, the most related variable is selected as the neural network features.

Table- I: The testing period for six weeks

\begin{tabular}{|c|l|}
\hline Week & \multicolumn{1}{|c|}{ Testing Period } \\
\hline 1 & $26^{\text {th }}$ April $-2^{\text {nd }}$ May \\
\hline 2 & $3^{\text {rd }}$ May $-9^{\text {th }}$ May \\
\hline 3 & $26^{\text {th }}$ June $-1^{\text {st }}$ August \\
\hline 4 & $2^{\text {nd }}$ August $-8^{\text {th }}$ August \\
\hline 5 & $13^{\text {th }}$ December $-19^{\text {th }}$ December \\
\hline 6 & $20^{\text {th }}$ December $-26^{\text {th }}$ December \\
\hline
\end{tabular}

Fig. 1 shows the flowchart of research methodology for the hybrid of the neural network and genetic algorithm. The input and output are then normalized between $[-1,1]$. The GAs will select many features from the input for the neural network training. The hidden layer can be varied on their circumstances - some only require a single hidden layer, and in other cases, require more [24].

In this paper, the hyperbolic tangent transfer function with a single hidden layer is used in the neural network learning, while the pure linear activation function is used for the output layer. The number of hidden neurons in the hidden layer is set as 1 and 2. The best number of hidden neuron is selected for neural network training. In (1) represents the hyperbolic tangent transfer function.

$$
S(x)=\tanh (x)=\frac{\theta^{x}-\theta^{-x}}{\theta^{x}+\theta^{-x}}(1)
$$

The GA will then help optimize the parameters of the neural network, the rate of learning, and the rate of momentum. The rate of learning is the portion of the error gradient, in which the weights must be adjusted. The rate of momentum reduces the proportion of the former weights in order to assess the new weights [25]. Both the rate of learning and the rate of momentum may vary between 0 and 1 .

The fitness value based on the Mean Absolute Error Percentage (MAPE) will determine the accuracy of the models. The MAPE is calculated in (2).

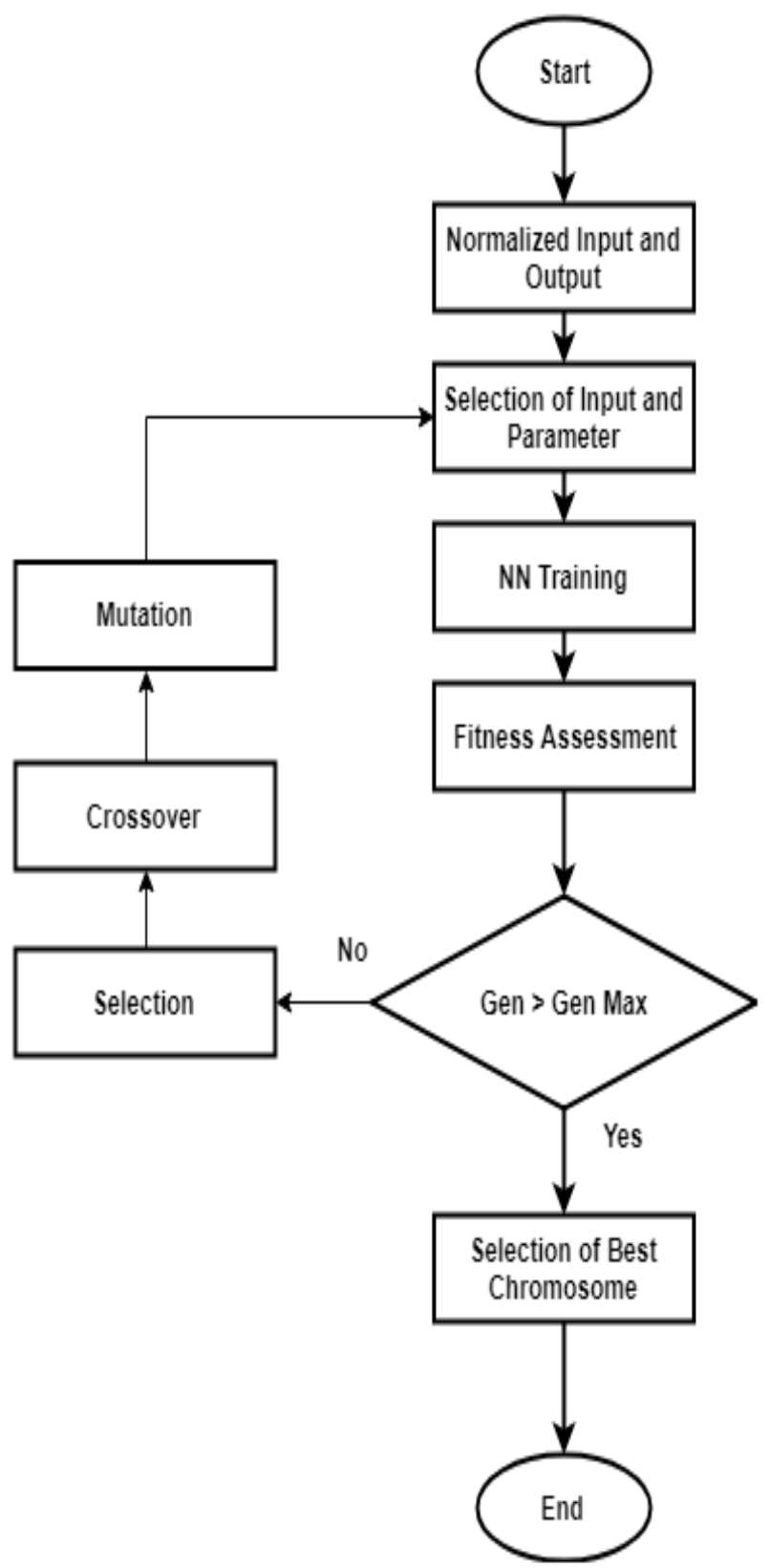

Fig. 1.The flowchart of methodology.

Published By Blue Eyes Intelligence Engineering \& Sciences Publication 


$$
\text { MAPE }=\frac{100}{m} \times \sum_{t=1}^{m} \frac{\left|P_{a x t_{t}}-P_{\text {forra }_{t}}\right|}{P_{\text {act }_{t}}}
$$

wherem - the total amount of hours, $P_{\text {act }_{t}}$ - the actual HOEP at hour $t$ and $P_{\text {fors }}$ - the predicted HOEP at hour t.

The best MAPE from the number of features and neural network parameters will be selected for every testing week.

\section{RESULTS AND DISCUSSION}

Table II shows the rate of learning, rate of momentum, and MAPE for the hybrid of the neural network and genetic algorithm (NN-GA). The GAs select several features to be an input for the neural network then optimize the rate of learning and the rate of the momentum of the neural network to be trained.

For week one, the optimum rate of learning and the rate of momentum is 0.75 and 0.45 , while for week two is 0.93 and 0.61 , respectively. The optimum rate of learning and rate of momentum for week three are 0.76 and 0.84 , while week four is 0.13 and 0.18 . The optimum rate of learning for week five is 0.33 , and week six is 0.59 , while the rate of momentum for week five and week six are 0.16 and 0.89 , respectively. The suitably hidden neuron for all week except for week four is 2, while for week four is 1 .

Fig. 2 and Fig. 3 show the actual versus the forecasted HOEP for week one and week two, respectively. The forecasted HOEP is plotted based on a total of 168 hours in a week. The MAPE for week one is $13.56 \%$, while for week two is $14.88 \%$. For week one, there is a sudden spike price at hour 108109 (30th April 2004), which the NN-GA had hardly capture the spike price. The actual HOEP at hour 108 is $153.11 \mathrm{\$} / \mathrm{MWh}$ while the GANN is $53.81 \mathrm{\$} / \mathrm{MWh}$. For week 2 , there are two points that both of the prediction fails to spot the price, which results in the difference between the prediction and the actual HOEP being bigger than $50 \%$. At hour 148 (9th May 2004), the actual HOEP is 13.89 \$/MWh while the NN-GA is $23.59 \$ / \mathrm{MWh}$. Whereas, at hour 151 (9th May 2004), the actual HOEP is 18.04 \$/MWh while the NN-GA is $31.79 \$ / M W h$. The graph from week two shows that the actual HOEP is quite volatile and has many spikes compared to week one. That explained the MAPE for week two is higher than week one.

Table- II: MAPE for the hybrid of NN-GA

\begin{tabular}{|l|l|l|l|l|}
\hline Week & $\begin{array}{l}\text { Hidden } \\
\text { Neuron }\end{array}$ & $\begin{array}{l}\text { Rate of } \\
\text { Learning }\end{array}$ & $\begin{array}{l}\text { Rate of } \\
\text { Momentum }\end{array}$ & $\begin{array}{l}\text { MAPE } \\
(\%)\end{array}$ \\
\hline 1 & 2 & 0.75 & 0.45 & 13.56 \\
\hline 2 & 2 & 0.93 & 0.61 & 14.88 \\
\hline 3 & 2 & 0.76 & 0.84 & 13.23 \\
\hline 4 & 1 & 0.13 & 0.18 & 13.97 \\
\hline 5 & 2 & 0.33 & 0.16 & 13.16 \\
\hline 6 & 2 & 0.59 & 0.89 & 13.95 \\
\hline \multicolumn{4}{|l|}{ Average } & 13.79 \\
\hline
\end{tabular}

The average MAPE for the proposed method of the hybrid of the neural network and genetic algorithm for the Ontario energy market is $13.79 \%$. The MAPE is improved as compared to the NN1, NN2 and NN3 models which are $24.45 \%, 16.79 \%$, and $15.70 \%$, respectively. The MAPE is improved as the proposed method is using the GAs to optimize the neural network parameter and selection number of the feature while the three models [23] is using the standalone neural network. Fig. 4 shows the comparison of MAPE for the NN-GA, NN1, NN2, and NN3. Based on the MAPE comparison for all six weeks, the NN-GA outperforms all the three models.

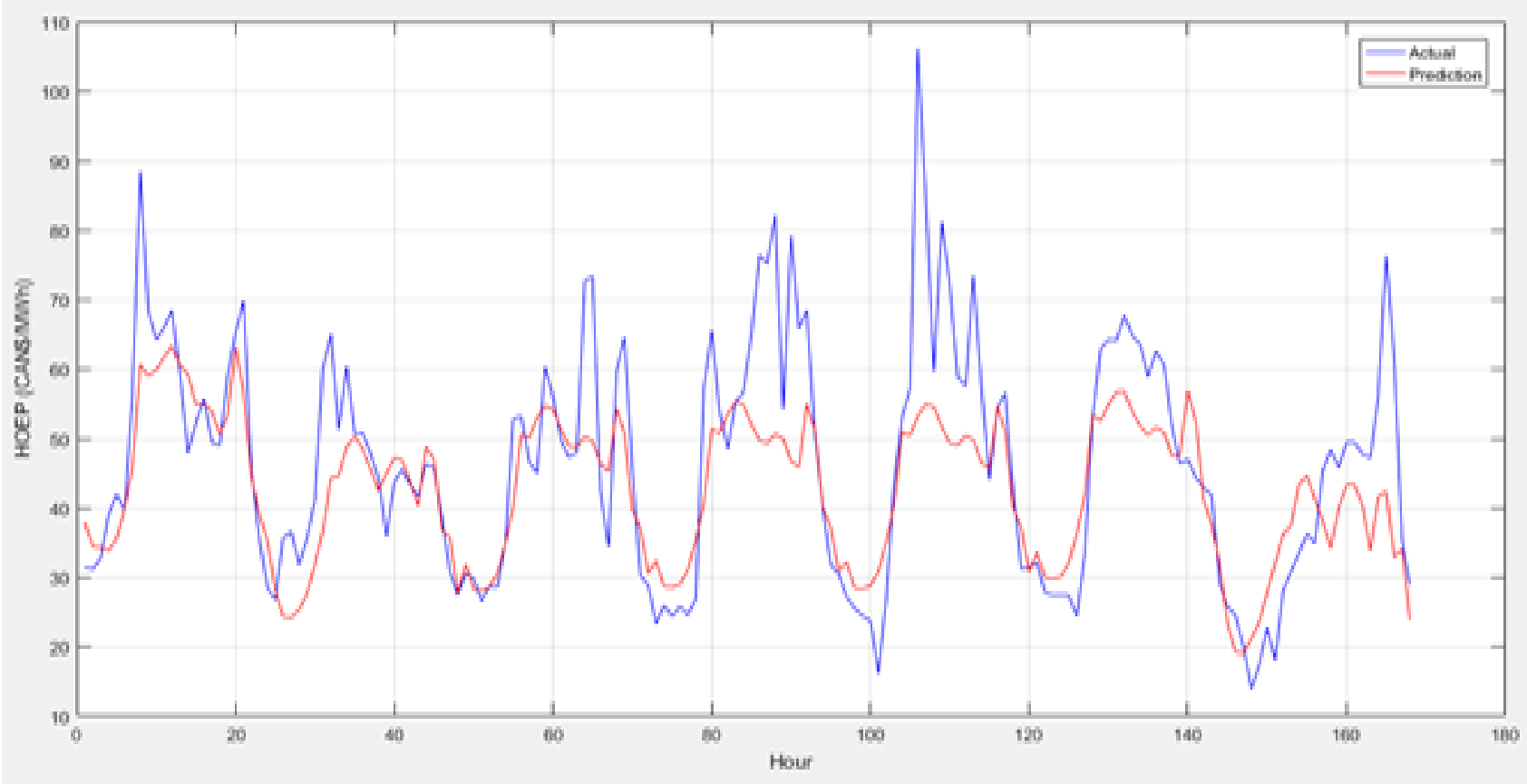

Fig. 2.The actual and prediction of electricity price for week 1. 


\section{ELECTRICITY PRICE FORECASTING USING A HYBRID OF NEURAL NETWORK AND GENETIC ALGORITHM}

The MAPE is improved as compared to the NN1, NN2 and NN3 models which are $24.45 \%, 16.79 \%$, and $15.70 \%$ respectively. The MAPE is improved as the proposed method is using the GAs to optimize the neural network parameter and selection number of the feature while the three models [23] is using the standalone neural network. Fig. 4 shows the comparison of MAPE for the NN-GA, NN1, NN2, and NN3. Based on the MAPE comparison for all six weeks, the NN-GA outperforms all the three models.

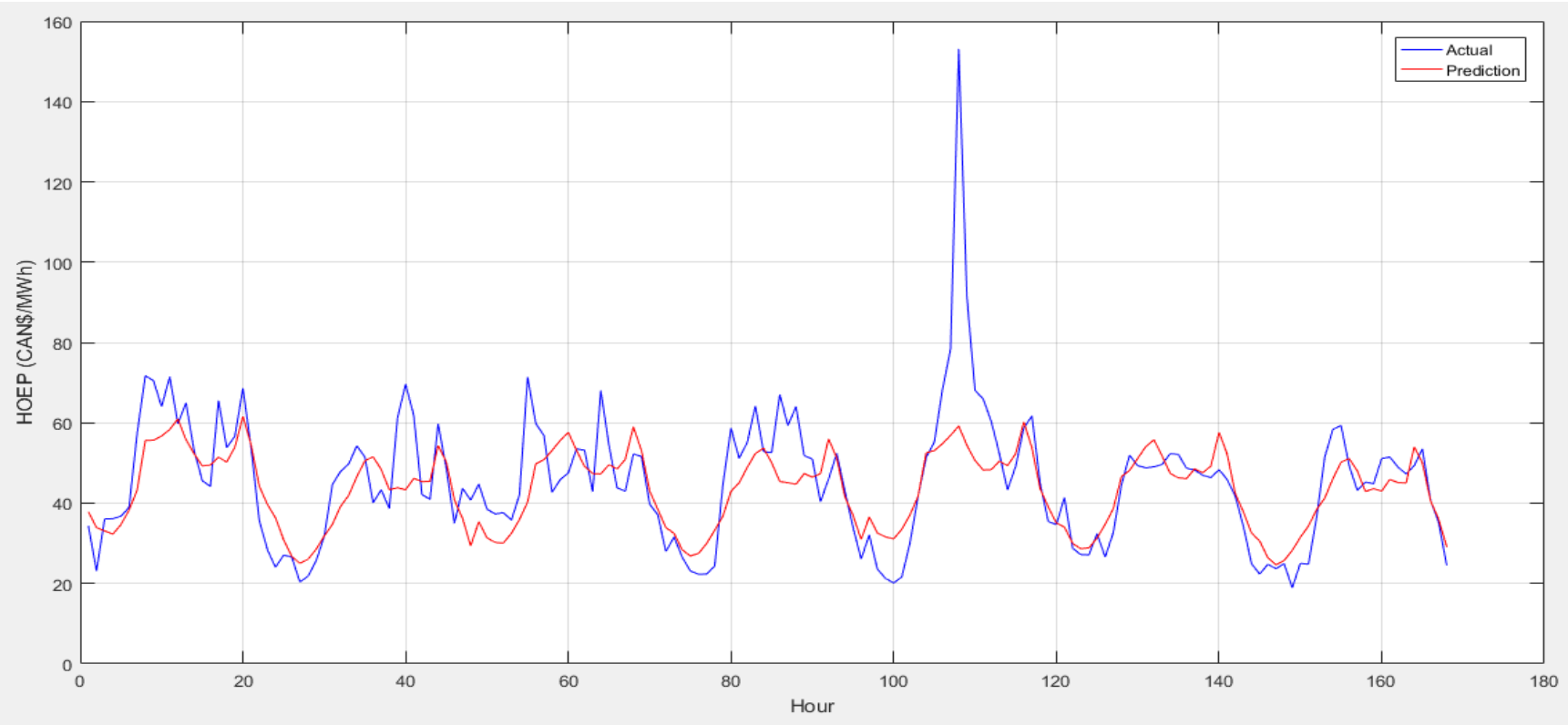

Fig. 3. The actual (blue) and prediction (red) of electricity price for week 2

Table- III: MAPE comparison for the NN-GA and other models

\begin{tabular}{|l|l|l|}
\hline Reference & Method & MAPE (\%) \\
\hline Proposed method & NN-GA & 13.79 \\
\hline \multirow{3}{*}[23]{} & NN1 & 24.45 \\
\cline { 2 - 3 } & NN2 & 16.79 \\
\cline { 2 - 3 } & NN3 & 15.70 \\
\hline
\end{tabular}

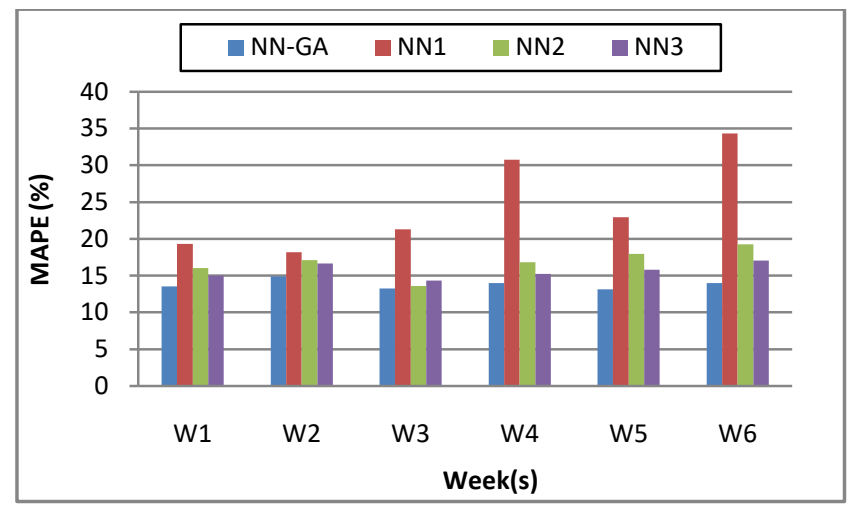

Fig. 4.Comparison of MAPE for NN-GA, NN1, NN2, and NN3.

\section{CONCLUSION}

This paper proposed the NN-GA for the Ontario energy market. The six weeks of electricity price were forecasted and compared with previous research. The accuracy of the prediction for all six weeks is better than compared models. The MAPE for this hybrid method is improved as the genetic algorithms assisted in optimizing the features and the neural network parameters.

For further recommendation, the electricity price forecasting using the neural network for the Ontario electricity market may consider other optimizing or preprocessing technique to improve the neural network performance and to promote the accuracy of prediction as the electricity price for the Ontario energy market is quite volatile.

\section{REFERENCES}

1. H. L. Willis and L. Philipson, Understanding Electric Utilities and De-Regulation. Florida: CRC Press, 2005.

2. H. Shayeghi and A. Ghasemi, "Day-ahead electricity prices forecasting by a modified CGSA technique and hybrid WT in LSSVM based scheme," Energy Convers. Manag., vol. 74, pp. 482-491, 2013.

3. S. Voronin, J. Partanen, and T. Kauranne, "A hybrid electricity price forecasting model for the Nordic electricity spot market," Int. Trans. Electr. Energy Syst. vol. 24, no. 5, pp. 736-760, 2014.

4. H. Mori and A. R. Model, "Integration of improved GRBFN with fuzzy clustering for electricity price forecasting," IEEE Joint 17th World Congress of International Fuzzy Systems Association and 9th International Conference on Soft Computing and Intelligent Systems, 2017, pp. 1-6.

5. Z. Tan, J. Zhang, J. Wang, and J. Xu, "Day-ahead electricity price forecasting using wavelet transform combined with ARIMA and GARCH models," Appl. Energy, vol. 87, no. 11, pp. 3606-3610, 2010.

6. M. Negnevitsky, Artificial Intelligence: A Guide to Intelligent Systems. England: Pearson Education Limited, 2005.

7. S. K. S. Aggarwal, L. M. L. Saini, and A. Kumar, "Electricity price forecasting in Ontario electricity market using wavelet transform in artificial neural network based model,” Int. J. Control. Autom. Syst., vol. 6, no. 5, pp. 639-650, 2008. 
8. I. P. Panapakidis and A. S. Dagoumas, "Day-ahead electricity price forecasting via the application of artificial neural network based models," Appl. Energy, vol. 172, pp. 132-151, 2016.

9. M. Ortiz, O. Ukar, F. Azevedo, and A. Múgica, "Price forecasting and validation in the Spanish electricity market using forecasts as input data," Int. J. Electr. Power Energy Syst., vol. 77, pp. 123-127, 2016.

10. S. Anbazhagan and N. Kumarappan, "Day-ahead deregulated electricity market price forecasting using recurrent neural network," IEEE Syst. J., vol. 7, no. 4, pp. 1-1, 2012.

11. Z. Wang, F. Liu, J. Wu, and J. Wang, "A hybrid forecasting model based on bivariate division and a backpropagation artificial neural network optimized by chaos particle swarm optimization for day-ahead electricity price,” Abstr. Appl. Anal., vol. 2014, pp. 1-31, 2014.

12. O. Abedinia, N. Amjady, M. Shafie-Khah, and J. P. S. Catalão, "Electricity price forecast using Combinatorial Neural Network trained by a new stochastic search method," Energy Convers. Manag., vol. 105, pp. 642 654, 2015.

13. Z. Yang, L. Ce, and L. Lian, "Electricity price forecasting by a hybrid model, combining wavelet transform, ARMA and kernel-based extreme learning machine methods," Appl. Energy, vol. 190, pp. 291-305, 2017.

14. A. Khamis and P. H. Yee, "A hybrid model of artificial neural network and genetic algorithm in forecasting gold price," vol. 3, no. 6, pp. 10-14, 2018.

15. D. J. Montana and L. Davis, "Training feedforward neural networks using genetic algorithms," 11th International Joint Conference on Artificial Intelligence, 1989, pp. 762-767.

16. S. Voronin and J. Partanen, "Price forecasting in the dayahead energy market by an iterative method with separate normal price and price spike frameworks," Energies, vol. 6, no. 11, pp. 5897-5920, 2013.

17. I. Shaft, J. Ahmad, S. I. Shah, and F. M. Kashif, "Impact of varying neurons and hidden layers in neural network architecture for a time frequency application," 10th IEEE Int. Multitopic Conf., pp. 188-193, 2006.

18. I. Azmira, W. Abdul, and I. Zainal, "A novel hybrid method of LSSVM-GA with multiple stage optimization for electricity price forecasting," IEEE International Conference on Power and Energy pp. 390-395, 2016.

19. K. Sarada and P. V. B. Raju, "Comparison of day-ahead price forecasting in energy market using neural network and genetic algorithm," IEEE International Conference on Smart Electric Grid pp. 1-5, 2014

20. D. A. Coley, An Introduction to Genetic Algorithms for Scientists and Engineers. Singapore: World Scientific Publishing, 1999.

21. E. Elbeltagi, T. Hegazy, and D. Grierson, "Comparison among five evolutionary-based optimization algorithms," Advanced Engineering Informatics, vol. 19, pp. 43-53, 2005.

22. Independent Electricity System Operator (IESO). (2019). Data directory. [Online]. Available: http://www.ieso.ca/en/power-data/data-directory.

23. N. N. A. N. Ibrahim, I. A. W. A. Razak, S. S. M. Sidin, and Z. H. Bohari, "Electricity price forecasting using neural network with parameter selection," in Intelligent and Interactive Computing, V. Piuri, V. Balas, S. Borah and S. Syed Ahmad, Eds. Singapore: Springer, 2019, pp. 141-148.

24. T. Kavzoglu, "Determining optimum structure for artificial neural networks," 25th Annual Technical Conference and Exhibition of the Remote Sensing Society, pp. 675-682, 1999.
25. J. P. S. Catalao, S. J. P. S. Mariano, V. M. F. Mendes, and L. A. F. M. Ferreira, "Short-term electricity prices forecasting in a competitive market: A neural network approach," Electr. Power Syst. Res., vol. 77, no. 10, pp. 1297-1304, 2007.

\section{AUTHORS PROFILE}

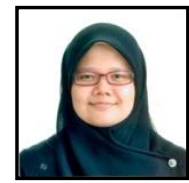

N.N.A.N.Ibrahim is currently pursuing a master of electrical engineering at UniversitiTeknikal Malaysia Melaka. She had received the bachelor of electrical engineering (Industrial Power) at UniversitiTeknikal Malaysia Melaka in the year 2017. Her research interests are electricity price forecasting, load forecasting and artificial neural network.

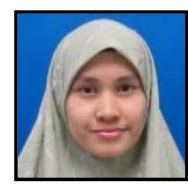

I.A.W.A.Razakis senior lecturer of Industrial Power Department of Faculty of Electrical Engineering UniversitiTeknikal Malaysia Melaka. She had received the $\mathrm{PhD}$ of engineering at UniversitiTenagaNasional. She gained her master of engineering at UniversitiTeknologi Malaysia. Her research interests are electricity load forecasting, electricity price forecasting and Bacterial Foraging Optimization Algorithm.

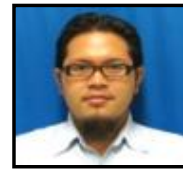

Z.H.Bohari is a senior lecturer of Faculty of Electrical and Electronic Engineering Technology, UniversitiTeknikal Malaysia Melaka. He had received the master of engineering at UniversitiTenaga Malaysia. He had gained bachelor of engineering at UniversitiKebangsaan Malaysia His research interests are artificial intelligence, renewable energy and transmission network system. 